hydrocarbon may not be the best explanation of the two surface energy states of a gold surface.

Recent studies of the surface of solids show that a gold surface may exist either with its bulk atomic properties (unreconstructed surface) or with shorter (reconstructed) atom bond lengths at the surface. This could be the reason for the apparent experimental duality which exists, with the unreconstructed surfaces behaving in a hydrophylic manner while the reconstructed surfaces show hydrophobic behaviour.

The question of whether gold is hydrophobic or hydrophilichas engineering consequences. One of these is the dropwise condensation of water vapour in heat exchanges.

Electrodeposited or evaporated gold surfaces of thickness greater than $200 \mathrm{~nm}$, unlike those of steel or copper, show dropwise condensation. J.W. Westwater reviewed the state of the art in this journal (21), and commented in the following terms: 'dropwise condensation will have commercial application as soon as the troublesome problem of how to main tain it for a long time period is solved. Gold may offer the solution or indicate how to obtain the solution'.

Either gold has a unique behaviour towards organic contaminants or gold surfaces exist in two energetic states. Further work should aim towards obtaining experimental evidence for one or the other explanation found in the current literature.

Besides the above application it is of great interest to the jewellery industry that reliable adhesive joints to gold be developed, and achieving this goal may change much of the present art and technology involved in the working of jewellery alloys.

\section{References}

1 A.W. Adamson, 'Physical Chemistry of Surfaces', 3rd Edition, Wiley, 1976

2 D. Maugis, 'Le Vide' 186, 1977, pp. 1-19, and in 'Microscopic Aspects of Adhesion and Lubrication', edited by J.M. Georges, Elsevier, 1982

3 F.M. Fowkes, in 'Treatise on Adhesion and Adhesives', Vol. 1, edited by R.L. Patrick, M. Dekker, 1966

4 A.A. Griffith, Phil. Trans. Roy. Soc., 1920, A221, 163-198

5 E.H. Andrews, Org. Coat. Appl. Polym. Sci. Proc, 1982, 47, 328-331

6 D. Maugis and M. Barquins, J. Phys. D. Appl. Phys., 1978, 77, 1989-2023

7 J. Schultz and A.N. Gent, J. Chem. Phys., 1973, 70, 708

8 A. Gent, Rubber Technol., 1947, 47, 202

9 F.M. Fowkes, Adv. Chem. Ser., 1964, 43, 99

10 D.H. Kaelble, 'Physical Chemistry of Adhesion', Wiley, 1971

11 F.M. Fowkes, in 'Microscopic Aspects of Adhesion and Lubrication', edited by J.M. Georges, Elsevier, 1982

12 'Handbook of Chemistry and Physics', 60th Edition, CRC, 1979

13 A.H. Cottrell, 'The Mechanical Properties of Matter', J. Wiley, 1964

14 A.A.V. Grosse, J. Inorg. Nucl. Chem, 1964, 26, 1349

15 H. Schonhorn, J. Phys. Chem., 1967, 71, 4578

16 R.A. Erb, J. Phys. Chem., 1965, 69, 1307

$17 \mathrm{~J}$. Cognard and C. Boichard, in 'Addhesion', Vol. 8, edited by K.W. Allen, Elsevier Applied Science, pp. 169-193, 1983

18 K.W. Bewig and W.A. Zisman, J. Phys. Chem., 1964, 68, 1804

19 E. Thelen, J. Phys. Chem., 1967, 71, 1946-1948

20 F.M. Fowkes, Ind. Eng, Chem., 1964, 56, 40

21 J.W. Westwater, Gola Bull., 1981, 14, (3), 95-101

22 K.W. Bewig and W.A. Zisman, J. Phys. Chem., 1965, 69, 4238

23 G. Valette, J. Electroanal. Chem., 1983, 139, 285-302

24 J. Clavillierand C. Neuyen van Huong, J. Electroanal. Chem, 1973, 41, 193. (In the original work it was stated that gold was the most hydrophobic metal. In a recent discussion with J. Clavillier he advised it to be expressed as the "less hydrophilic metal')

25 M.L. White, J. Phys. Chem., 1964, 68, 3083-3085

26 T. Smich, J. Coll. Int. Soi., 1980, 75, 51-55

27 G.L. Gaines Jr., J. Coll. Int. Sci., 1981, 79, 295

28 M. Schnecgans and E. Mencel, J. Coll. Int. Sci, 1982, 88, 97-99

29 R. Feders, Surf. Sci, 1977, 68, 229-235

30 M.A. Van Hove, Surf. Sci., 1979, 81, 1-7

\title{
Electropolishing of Gold
}

One of the aspects of gold working which has always been open to improvement, in particular with regard to the large jewellery manufacturing industry, is that of surface finishing of the gold piece. Mechanical finishing (polishing) is time consuming and requires skilled personnel. Electrolytic polishing in which gold is removed anodically in a solution in a controlled manner to give a bright finish has been used but is susceptible to a number of obstacles, chief of which is the difficulty of achieving a consistent finish on alloys of different caratage and containing different alloying elements. Most electropolishing which is carried out on gold alloys is effected in toxic cyanide solutions, which means that special precautions are needed to ensure safety.

Recent work reported by J. Verlinden, J.P. Celis and J.R. Roos ('Passivity of Metals and Semiconductors', edited by M. Froment, Elsevier Science Publishers, Amsterdam, 1984) on the passivationdepassivation behaviour of gold in a hydrochloric acid-glycerol solution for the purpose of thinning electrodeposited gold samples for TEM examination, extends our understanding of the subject and, if applicable to gold alloys, might well have significant practical applications in other areas.

Previous work on the anodic behaviour of gold in hydrochloric acid solutions had shown that when the gold electrode was held in acertain potential range the current oscillated periodically and this was thought to be due to two competing processes viz. the formation of $\mathrm{Au}$ (III) oxide at the electrode surface and the redissolution of this oxide by the chloride ions present in the solution. Such behaviour, if controlled, might lead to useful polishing of the gold surface and Verlinden et al. have found that modifying the electrolyte by the addition of glycerol reduced the gold dissolution rate to the extent that this could be achieved.

Pure gold deposits with different morphologies were formed from additive-free cyanide gold plating solutions by varying the cathodic current densities. Anodic polarization runs with these specimens in hydrochloric acid-glycerol (25:75 weight per cent) solutions at room temperature revealed a passivation potential, due to the formation of an $\mathrm{Au}$ (III)oxide film, which was independent of the structure and morphology of the gold surface. At potentials close to that of passivation periodic oscillations of current occurred similar to those previously obtained with unmodified hydrochloric acid solutions, and high quality electropolishing of the gold surface was obtained. The quality of the surface finish appeared to be virtually independent of the initial specimen topography and structure.

Further improved control of the thinning process was achieved by applying a cyclic potential sweep between the active and passive ranges, so controlling the frequency of current oscillations and the times for which the surface was in the active and passive regions.

It will be interesting to see whether these potentially useful results can be extended and applied to practical gold alloys. 